\title{
Adult Lymphocyte-Depleted Classic Hodgkin Lymphoma
}

National Cancer Institute

\section{Source}

National Cancer Institute. Adult Lymphocyte-Depleted Classic Hodgkin Lymphoma. NCI

Thesaurus. Code C9125.

Lymphocyte-depleted classic Hodgkin lymphoma occurring in adults. 